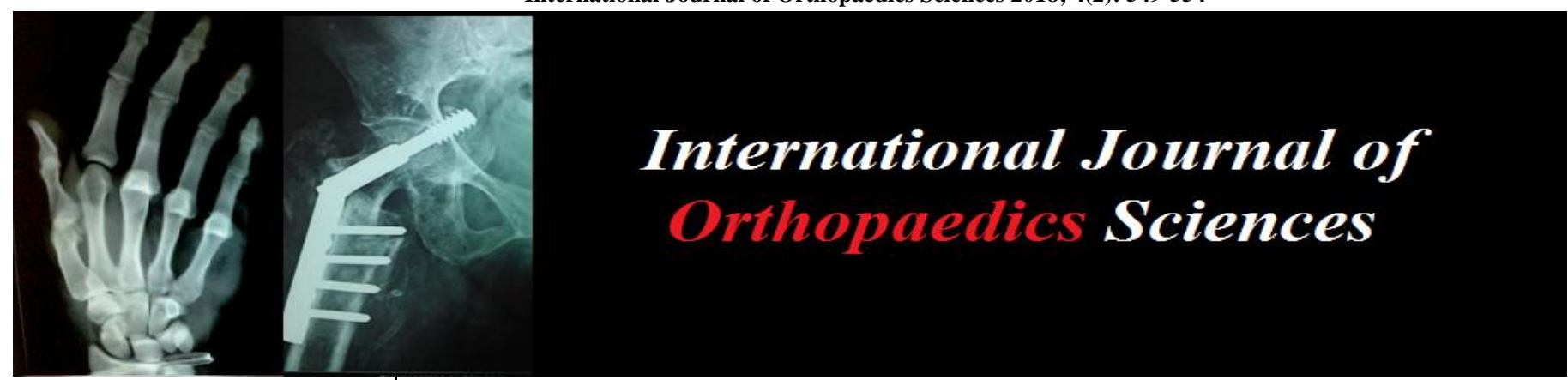

ISSN: $2395-1958$

IJOS 2018; 4(2): 549-554

(C) 2018 IJOS

www.orthopaper.com

Received: 21-02-2018

Accepted: 22-03-2018

Ahmed Alkhuzai FICMS

Faculty of Medicine Sulaimani

University, Iraq
Correspondence

Ahmed Alkhuzai FICMS

Faculty of Medicine Sulaimani

University, Iraq

\section{A prospective comparative study to compare orthobiological PRP platelet rich plasma intra lesional injectional therapy compare to steroid injection in treatment of Achilles tendonitis and intractable plantar fasciitis a clinical follow up study for 2 Years}

\author{
Ahmed Alkhuzai FICMS
}

DOI: https://doi.org/10.22271/ortho.2018.v4.i2i.81

Abstract

Background: Achilles Tendonitis and intractable Chronic Plantar Fasciitis are a common orthopedic condition that can prove difficulty in treatment successfully. Tendon injury often become chronic because of poor blood supply to these areas. The high rates of relapses of plantar fasciitis, with a wide complications rate of rupture tendon especially in Achilles Tendonitis, they were treated by local steroid injection. That lead to evaluate another Method in treatment of soft tissue inflammatory Tendonitis by the use of Orthobiologics method PRP Platelets Rich Plasma therapy offers a promising solution to accelerate healing of tendon injuries in treatment of these intractable tendonitis.

Aim of study: We studied the effectiveness of the Orthobiologics PRP Platelets Rich plasma, intralesional injection in chronic inflammatory soft tissue Tendonitis Plantar Fasciitis, Achilles Tendonitis, in Compare to intralesional steroid injection treatment of chronic inflammatory soft tissue tendonitis to evaluate the success and relapse rate of inflammation process for 2 years follow up.

Methods: Patients with inflammatory soft tissue Tendonitis, plantar fasciitis\& Achilles Tendonitis not responded to a minimum of 1-year standard conservative management were offered PRP therapy. In this prospective comparative study of 100 patients with inflammatory soft tissue Tendonitis, Achilles Tendonitis and plantar fasciitis, in private clinic sector sharing with blood bank in Sulaimani teaching Hospital center of Sulaimaniyah city, from May 2010 till June 2012. were randomized according to inclusion exclusion criteria into two groups. Group A, 50 patients all of them with chronic inflammatory Tendonitis with failure of other modalities of conservative treatments, they receive PRP Platelets Rich Plasma injections of 3 to $5 \mathrm{ml}$ PRP from blood of the same patient were collected \& separated in plasma cell separation department of blood bank in Sulaimaniyah teaching Hospital center. Group B, 50 patients were treated by Steroid injection, for the same inflammatory soft tissue tendonitis, Achilles Tendonitis \& plantar fasciitis. The follow up times were 12, and 24 months.

Results: We used two important scoring systems for assessment \& evaluation of the results of this procedure, during follow up assessment of these patients, there were no systemic or local complications were noted at any time. The pain was reported by patients according to VAS Score were (78.\%) in 12 months \& $(80 \%)$ in 24 months, they have No pain, Mild or moderate pain in group A, were treated by PRP therapy. However, the VAS score for Cortisone are 25\% at 12 months, $23 \%$ at 24 months for No pain level, mild and moderate pain scoring level, with $75 \%, 77 \%$ of severe pain and excruciating pain for same time of follow up, according to criteria of the Roles and Maudsley score for PRP at 12 months, 24 months results were rated $85 \%, 94 \%$ as excellent \& good scoring, for group A, were PRP therapy used. However, the results for same time in group B, were used Cortisone therapy are 32\%, 20\% as excellent \& good scoring rate. That meaning low rate of improvement with Cortisone usage in compared to high rate of improvement according to criteria of the Roles and Maudsley score, at the last follow-up $(p<0.01)$. \& Relapses of inflammations for second or third times.

Conclusions: We concluded that intralesional injection of PRP resulted in safe, significant reduction of inflammatory process, sustained improvement of pain, with high rate of functional outcome in compare to steroid intralesional injection for treatment of inflammatory soft tissue tendonitis (Achilles Tendonitis and intractable Plantar Fasciitis) a Clinical Follow up Study for 2 Years was more effective and durable than cortisone injection for the treatment of chronic recalcitrant cases of plantar fasciitis.

Keywords: PRP platelet rich plasma 


\section{Introduction}

Achilles Tendonitis and intractable Chronic Plantar Fasciitis are a common orthopedic condition that can prove difficulty in treatment successfully. Tendon injury often become chronic because of poor blood supply to these areas. Chronic problem that affects sport participants as well as inactive middle-aged individuals ${ }^{[6,19]}$. Plantar fasciitis is one of the most common causes of plantar heel pain encountered in orthopedic practice. As a clinical entity, it is characterized by gradual onset of sharp pain along the medial aspect of the heel that is worse with the first step taken in the morning or after prolonged sitting ${ }^{[10]}$. Histological findings of plantar fasciitis show no evidence of inflammation; rather, they show myxoid degeneration, microtears, collagen necrosis, and angiofibroblastic hyperplasia ${ }^{[10]}$. These findings suggest a chronic degenerative process, not an acute inflammatory one. The new treatment therapy regimens Platelet Rich Plasma (PRP), will initiate a healing response rather than suppress the inflammatory process, through multi factors available products from this therapy, should be effective treatment options ${ }^{[4]}$. In general, theses condition Achilles Tendonitis and intractable Chronic Plantar Fasciitis are self-limiting, and the majority of cases spontaneously resolve regardless of type of intervention received (including placebo) ${ }^{[4]}$. Increasing knowledge of the pathology has led to the widespread application of a different modalities of conservative treatments for Achilles Tendonitis and intractable Chronic Plantar Fasciitis ${ }^{[16]}$, including physiotherapy, plantar-fasciastretching exercises ${ }^{[8]}$, icepacks, night splints, heel padding insertion, shoe modification, nonsteroidal anti-inflammatory drugs (NSAIDs) and ultrasonic wave therapy, when conventional physical therapy alone is not effective ${ }^{[23]}$. The physical therapy, and night splints are regarded as the mainstay of plantar fasciitis treatment will provide substantial relief $80 \%$ of patients $[5,13,17]$. Steroid injection into the plantar fascia is an effective treatment of plantar fasciitis when conservative management is unsuccessful. However, the lack of an inflammatory process histologically in plantar fasciitis questions its mode of action. In adults, steroid injection has been associated with rupture of the plantar fascia in 2.4 to $10 \%$ of patients as well as attenuation of the plantar fat pad $[1,6,7,8,15,18]$. That lead to evaluate another method when other conservative modalities treatments not succeed.

What PRP; Super-Concentrated Platelets Help Accelerate Healing of Injured Tissues, how does Platelets (thrombocytes) Rich in Plasma that lead to healing, these are small diskshaped cells within blood of every one, that contain natural sources of growth factors, proteins and cytokines that stimulate the healing of bone and soft tissues ${ }^{[1,2,3]}$.

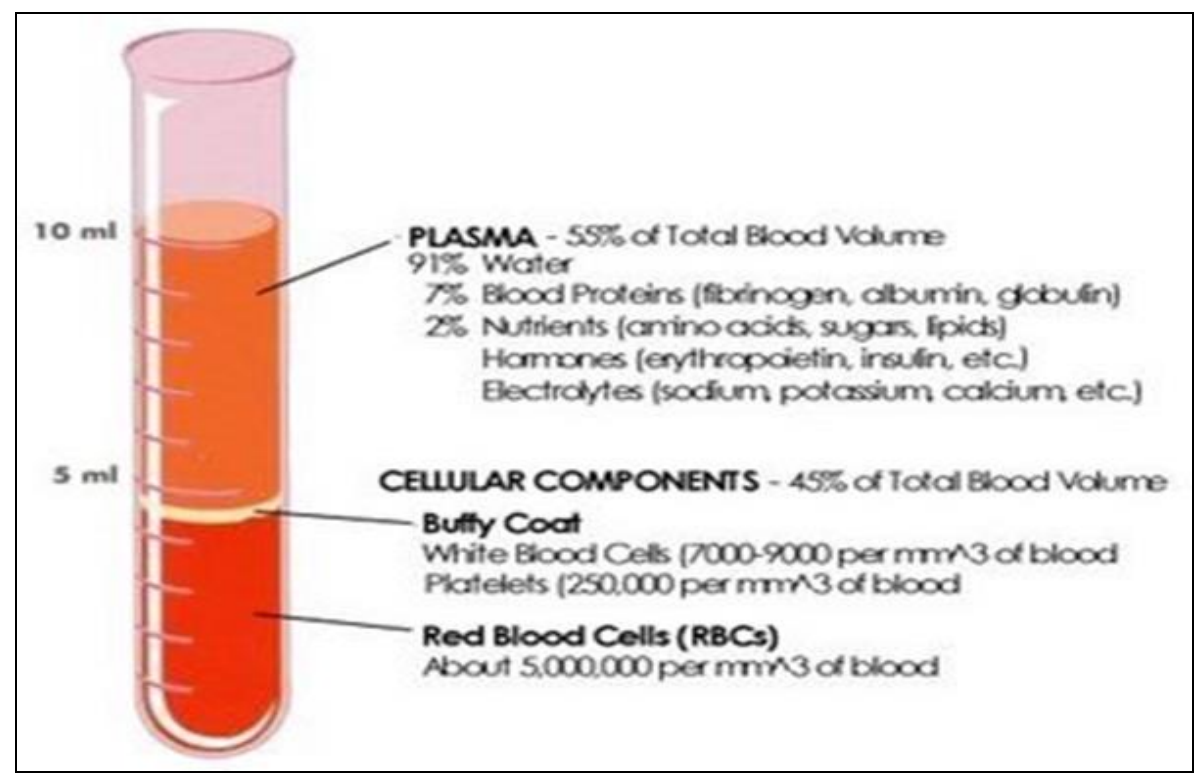

Fig 1: PRP Post Separation from Blood of Same Patient

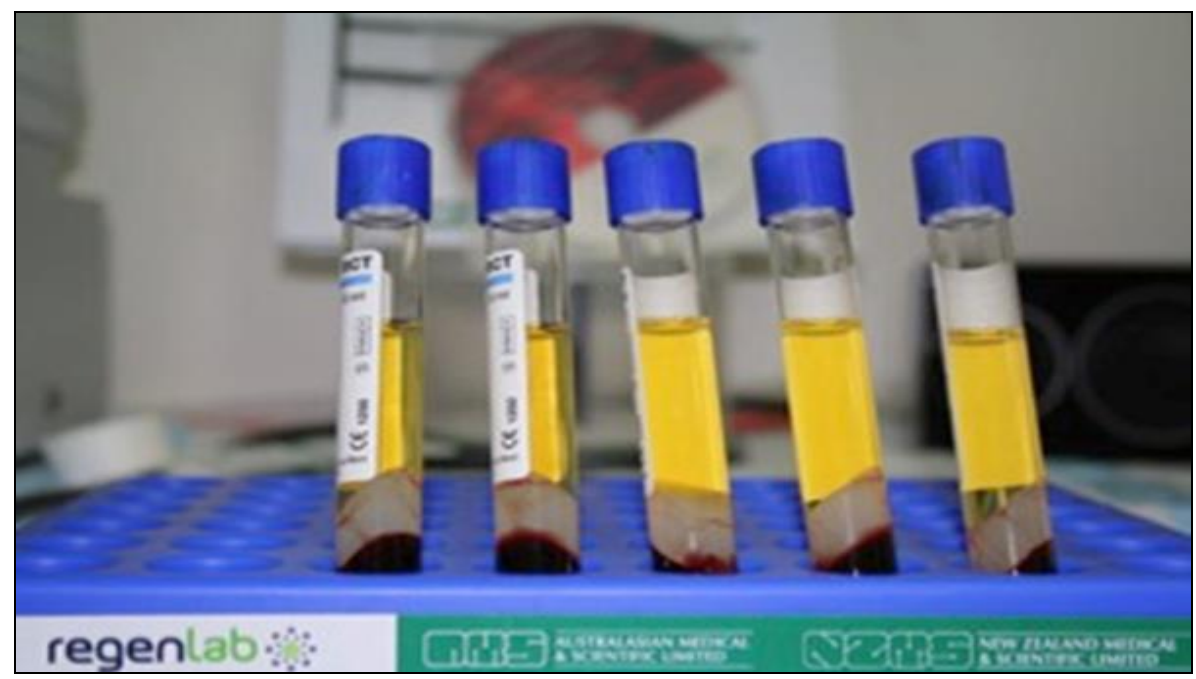

Fig 2: PRP Post Centrifuge Separation from the Blood $\sim 550 \sim$ 
PRP (Platelet-Rich Plasma) Therapy started at mid-1990 PRP has been used in operating procedures for several decades in wound healing, also used to stimulate bone formation in spinal fusion surgery. Recently, the inflammatory reaction serves several important purposes, that lead to stimulate the leukocytes facilitates in process of phagocytosis plus removal of the damaged cells and other particulate matter ${ }^{[9]}$. Pain and tenderness remind the patients to protect the injured area; however, the inflammatory reaction eventually becomes counterproductive. The extravascular pressure exerted by the edema will lead to decreases blood flow into the area eventually end in delay healing. Sometimes, the debris coagulates and forms hard masses, scarring, and/or trigger points in the muscle or joint, preventing function from returning to normal activities ${ }^{[13]}$. Platelet-rich plasma (PRP) has become a popular treatment option for a variety of orthopedic inflammatory conditions. PRP, the plasma fraction of the autologous blood having a platelet concentration above baseline, contains various growth factors that have been found to be involved in a host of biosynthetic pathways. By injecting a concentrated platelet-enriched plasma into a localized area, these growth factors are thought to jumpstart the regenerative processes in degenerative conditions. In chronic conditions, PRP causes restoration of the inflammatory process that commonly stoppage following failure of conservative treatment, transforming the chronic injury into a new acute injury with addition of concentrated growth factors. The primary outcomes of using PRP to treat plantar fasciitis, Achilles tendonitis have been favorable, however the results have come from very small center studies [3]. That requirement to increase the number of center evaluation of this procedure.

PRP has been used in outpatient settings for treatment of common overuse conditions including; Sacroiliac Joint, Iliolumbar Ligaments, Facet Joints, Interspinous Ligaments. Shoulders; Rotator Cuff--Partial Tears, Biceps Tendinosis, Chronic Glenohumeral Ligament Sprains, AcromioClavicular, Joint Dysfunction, Levator Scapulae Tendinosis. Elbows joint; Ulnar, Distal Biceps Tendon Partial Tear, Wrist \& Hand; Chronic Thumb Sprain, Joint Arthritis. Arthritic Joints; Hip/Pelvis/SI joints. Piriformis Syndrome, Greater Trochanteric Bursitis, Sacroiliac Joint Dysfunction, Hamstring Strain, Ischial Tuberosity Bursitis, Hip Joint Arthritis, Osteonecrosis of the Femoral Head, Symphysis Pubis Pain, Knee; Patellar Tendonitis/Tendinosis, OsgoodSchlatter's Disease, Quadriceps Strain or Partial Tear, Degenerative Arthritis, Rheumatoid Arthritis, Chondromalacia Patella, Lower Leg; Calf Pain, Ankle \& Foot; Chronic Ligament Strains, Chronic Achilles Tendinosis, Chronic Partial Tendon Tear, Plantar Fascitis [11, 15, 16, 17].

Recently, promising results were reported with the use of platelet-rich plasma (PRP) injections for treating muscle and tendon injuries and degenerative diseases $[9-13,15,21]$. The factors that lead using PRP is to increase tendon regenerative abilities with a high content of cytokines and cells, in hyper physiologic doses, that will be promote cellular chemotaxis, matrix synthesis, and proliferation ${ }^{[20]}$. There is an increase in vascular permeability, initiation of angiogenesis, chemotactic migration of monocytes and macrophages, and that will lead to formation of fibroblasts to synthesize collagen and extracellular matrix, within the first 7 days degranulation of the alpha granules in platelets will releases many different growth factors that can play a role in tissue regeneration processes, at approximately 10 weeks the remodeling process begins, which can last up to 2 years ${ }^{[20]}$.

The PRP Factors: 1. Platelet-derived growth factor 2. Transforming growth factor beta 3. Insulin-like growth factor 1, 4. Insulin-like growth factor 2, 5. Fibroblast growth factor, 6. Epidermal growth factor, 7. Vascular endothelial growth factor, 8. Interleukin 8, 9. Keratinocyte growth factor, 10. Connective tissue growth factor ${ }^{[9,4]}$.

PRP represents a treatment option for foot and ankle pathologies, including tendinopathy (Achilles, peroneal, posterior tibial, flexor hallucis longus, anterior tibial) and chronic ligamentous injury, such as plantar fasciitis ${ }^{[4,9]}$.

\section{Method}

This is prospective comparative study of 100 patients with inflammatory soft tissue Tendonitis, Achilles Tendonitis and plantar fasciitis. Were randomized according to inclusion exclusion criteria into two groups. Group A, 50 patients all of them with of Tendonitis inflammatory of chronic Achilles tendonitis and Intractable plantar fasciitis, post 12 months of different medical modalities treatments, 30 patients of them were plantar fasciitis, 20 of them were Achilles tendonitis. They receive PRP Platelets Rich Plasma injections of 3 to 5 $\mathrm{ml}$ PRP from blood of the same patient, were choose two to three maximal painful tenderness sites for injection, repeated two to three times once weekly according to patients clinical responding therapy, also excluded the injection of previous steroid therapy from the study. These procedures were collected \& separated in plasma cell separation department of Blood Bank in Sulaimaniyah Teaching Hospital Center of Sulaimaniyah city, were started from May 2010 till June 2012. Group B, 50 patients were treated by Steroid injection, for the same inflammatory soft tissue tendonitis, the plantar fasciitis 28 patients, and Achilles Tendonitis 22 patients, also excluded the previous steroid injection for same tendonitis. We follow up these patients regularly until 12, 24 months. All patients gave informed consent to participate in the study, which was carried out in accordance with the World Medical Association Declaration of Helsinki. Patients with inflammatory soft tissue Tendonitis plantar fasciitis\& Achilles Tendonitis not responded to a minimum of 1-year standard conservative management. We follow up these patients in times were 12, and 24 months. Patients experienced heel pain felt maximally over the plantar aspect for more than 12 months continuously and had radiographic evidence of calcaneal spur in $60 \%$ of the patients in group A and group B. Exclusion criteria included generalized inflammatory arthritis, ankylosing spondylitis, Reiter syndrome, rheumatoid arthritis or psoriatic arthritis, also any wound or skin lesion at the plantar aspect of the foot, or pregnancy, severe infection, any known malignancy, or bleeding disorder, also previous surgery for same diseases, or history of Corticosteroid injection into the heel, including Achilles tendon and plantar fasciitis, also excluded the local nerve-related symptoms such as radiculopathy, tarsal tunnel syndrome or tarsi sinus syndrome, and the foot and ankle osteoarthritis. The system allows supernatant (PRP) transfer from the 10-ml syringe under aseptic conditions. All patients received injections at the plantar fascia or Achilles tendon once per week repeated two to three times. The injection point was at the origin of the plantar fascia on the medial tubercle of the calcaneus, the origin of the plantar fascia was approached from the medial side of the foot but near the plantar surface, we choose two to three maximal pain sites, also in Achilles tendonitis two to three sites proximally \& distally. After injection, all patients 
allowed to immediately walk but we advised them to avoid full weight-bearing or sport activities, such as running or jumping, for at least three to four weeks after the last injection. The PRP injection, patients remained in the outpatient clinic until pain was considered tolerable and were followed in the outpatient clinic regularly every three months after the last injection to detect possible side effects or complications happen post therapy, the duration of follow up were for 12, and 24 months. Non-steroidal anti-inflammatory drugs NSAIDs were prescribed only for five days after injection, the ice packs were allowed on the site of post injection. Physiotherapy treatments started after three weeks post last injection.

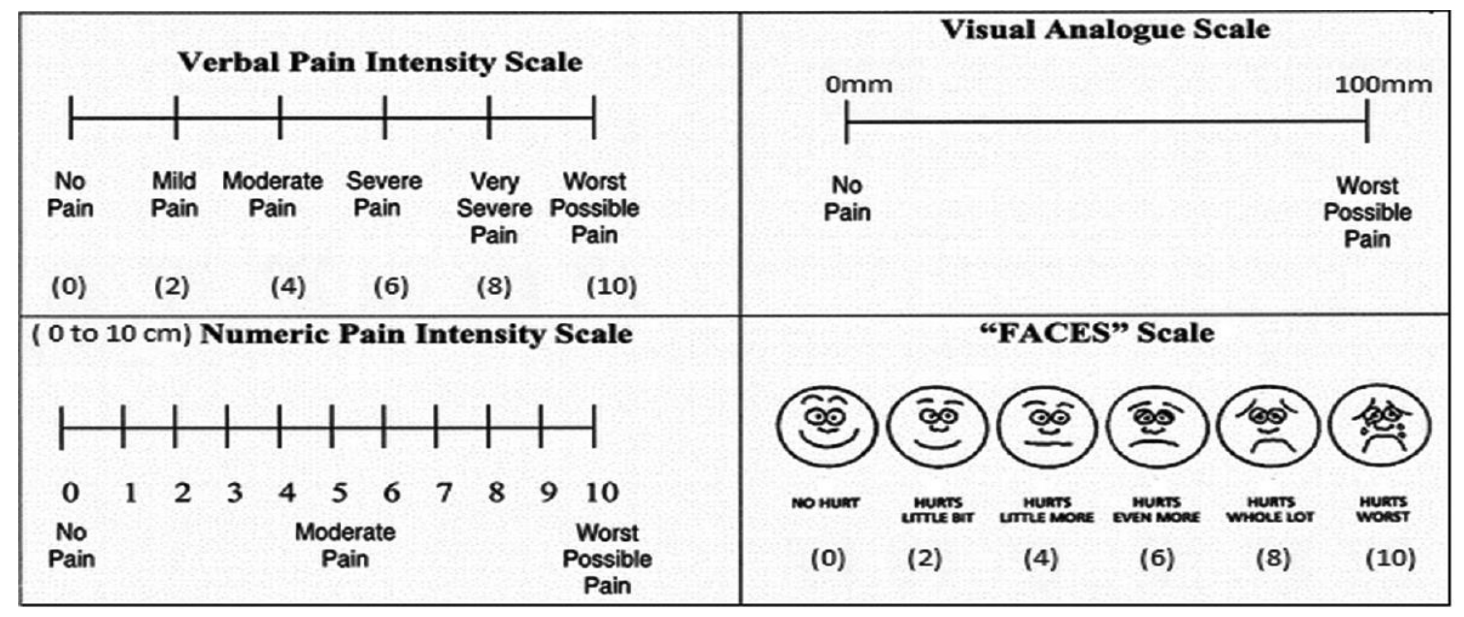

Fig 3: VAS Visual Analog Scale.

Before treatment and during the follow-up visit, these patients were evaluated to rate their level of pain on a visual analogue scale VAS have been used; no pain ( $0-4 \mathrm{~mm}$ ), mild pain (5$44 \mathrm{~mm})$, moderate pain $(45-74 \mathrm{~mm})$, and severe pain $(75-$
$100 \mathrm{~mm})$. The second score dependable in assessments of treatment of soft tissue inflammatory tendonitis, were used for the modified criteria of the Roles and Maudsley score.

\begin{tabular}{|lcl|}
\hline & Point & \multicolumn{1}{c|}{ Interpretation } \\
\hline $\begin{array}{l}\text { Excellent } \\
\text { Good }\end{array}$ & 1 & $\begin{array}{l}\text { No pain, full movement and activity } \\
\text { Occasional discomfort, full movement } \\
\text { and activity }\end{array}$ \\
Fair & 3 & Some discomfort after prolonged activity \\
Poor & 4 & Pain-limiting activities \\
\hline
\end{tabular}

Fig 4: Roles-Maudsley score

were used to assess the outcome of this procedure: The excellent score (no pain, patient satisfied with the treatment outcome and unlimited walking without pain), the good score result (symptoms substantially decreased, patient satisfied with the treatment outcome and ability to walk without pain for >one hour), acceptable\& fair (symptoms somewhat decreased, pain at a more tolerable level than before treatment and patient slightly satisfied with the treatment outcome) or poor (symptoms identical or worse and patient not satisfied with the treatment outcome).

Results: We used two scoring systems for assessment \& evaluation of the results of this procedure, during follow up assessment of these patients, there were no systemic or local complications were noted at any time. The pain was reported by patients according to VAS Score were (78.\%) in 12 months \& $(80 \%)$ in 24 months, when they have No pain, Mild or moderate pain in 12 months and 24 months in group A, were treated by PRP therapy. However, the VAS score for Cortisone are $25 \%$ at 12 months, $23 \%$ at 24 months for the No pain, mild and moderate pain scoring level, with $75 \%, 77 \%$ of severe pain and excruciating pain at 12, 24 months, the average VAS score 8.1 at 12 months, and 8.7 at 24 months. However, they have same rate before treatment by Cortisone in group B patients. These patients required icepack treatment and NSAIDs, Post treatment for pain resolved about two hours after infiltration. The VAS score follows up in 12 months, 24 months were improved for group A, when the PRP used for these patients with an average VAS score decreased significantly from 8.3 before treatment to 2.2 at 12 months, and 1.8 at 24 months., compared to group B, were used the Cortisone the average VAS score 8.1 before 12 months, and 8.7 at 24 months, have same rate before treatment without any obvious changes in the level.

Table 1: VAS Visual Analog Scale

\begin{tabular}{|c|c|c|c|c|c|c|}
\hline $\begin{array}{l}\text { Pain Intensity / visual } \\
\text { analogue scale (VAS)) }\end{array}$ & point & $\begin{array}{l}\text { visual analogue } \\
\text { scale MM / } 100\end{array}$ & $\begin{array}{l}\text { VAS / Cortisone } \\
\% 12 \text { months } \\
\end{array}$ & $\begin{array}{l}\text { VAS / Cortisone } \\
\% 24 \text { months } \\
\end{array}$ & $\begin{array}{l}\text { VAS / PRP } \\
\% 12 \text { months } \\
\end{array}$ & $\begin{array}{l}\text { VAS / PRP } \\
\% 24 \text { months } \\
\end{array}$ \\
\hline No pain & 0 & $0-5 \mathrm{~mm}$ & $7 \%$ & $8 \%$ & $40 \%$ & $56 \%$ \\
\hline Mild Pain & 1 & $5-44 \mathrm{~mm}$ & $6 \%$ & $4 \%$ & $20 \%$ & $20 \%$ \\
\hline Moderate Pain & 2 & $45-74 \mathrm{~mm}$ & $12 \%$ & $11 \%$ & $18 \%$ & $14 \%$ \\
\hline Sever Pain & 3 & $75-90 \mathrm{~mm}$ & $60 \%$ & $65 \%$ & $14 \%$ & $6 \%$ \\
\hline Excruciating Pain & 4 & $90-100 \mathrm{~mm}$ & $15 \%$ & $12 \%$ & $8 \%$ & $4 \%$ \\
\hline
\end{tabular}


Table 2: Roles-Maudsley score

\begin{tabular}{|c|c|c|c|c|c|c|}
\hline $\begin{array}{c}\text { Roles- } \\
\text { Maudsley score }\end{array}$ & Point & Interpretation & $\begin{array}{c}\text { Roles- } \\
\text { Maudsley score } \\
\text { Cortisone 12 } \\
\text { months }\end{array}$ & $\begin{array}{c}\text { Roles- } \\
\text { Maudsley score } \\
\text { PRP 12 } \\
\text { Months }\end{array}$ & $\begin{array}{c}\text { Roles- } \\
\text { Maudsley score } \\
\text { Cortisone 24 } \\
\text { months }\end{array}$ & $\begin{array}{c}\text { Roles- } \\
\text { Maudsley score } \\
\text { PRP 24 months }\end{array}$ \\
\hline Excellent & 1 & $\begin{array}{c}\text { No pain, Full Movement\& } \\
\text { Activities }\end{array}$ & $18 \%$ & $74 \%$ & $12 \%$ & $82 \%$ \\
\hline Good & 2 & $\begin{array}{c}\text { Occasional Discomfort, Full } \\
\text { Movement \& Activity }\end{array}$ & $14 \%$ & $11 \%$ & $8 \%$ & $12 \%$ \\
\hline Moderate Pain & 3 & $\begin{array}{c}\text { Some Discomfort after Prolong } \\
\text { Activities }\end{array}$ & $38 \%$ & $9 \%$ & $37 \%$ & $2 \%$ \\
\hline Severe Pain & 4 & Pain- Limiting Activities & $40 \%$ & $6 \%$ & $43 \%$ & $4 \%$ \\
\hline
\end{tabular}

According to criteria of the Roles and Maudsley score for PRP at 12 months, 24 months results were rated $85 \%, 94 \%$ as excellent \& good scoring, for group A, were PRP therapy used. However, the results for same time at 12, 24 months in group B, were used Cortisone therapy are $32 \%, 20 \%$ as excellent \& good scoring rate, at 12,24 months of follow-up. With $\mathrm{P}$ value $(p<0.01) .(p=0.001)$. Both groups, $\mathrm{A}$ and $\mathrm{B}$ patients there were significant improvements in the mean of RM score Roles-Maudsley, and VAS Visual Analogue score from baseline before treatment, in compare to post treatment therapy were seen at all follow up visit for 12, 24 months in group A superior than group B. Also, there were significant statistical differences, functional outcome with clinical improvements at 12, 24 months in group A treated by PRP superior to the group B were treated by steroid. With No systemic or local complications were noted at any time related to this therapy observed in treatment of soft tissue inflammatory tendonitis in compare to steroid injection were lead to rupture of tendon \& Relapses of inflammations for second or third times.

\section{Discussion}

The aim of the study was to evaluate the PRP Orthobiological treatment of chronic intractable plantar fasciitis, and Achilles Tendonitis using PRP for healing, plus evaluation the safety and resultants outcome of this method, this study for the therapy is randomized clinical trials to determine effectiveness for treatment these types of tendonitis. Although limited by many factors, results of our study revealed that two to three PRP injections will lead to improvement in VAS scoring index for pain, with high rate $78.6 \%$ of the patients, in compare to rate results post cortisone therapy which was low rate of pain improvements, also in RM score Roles-Maudsley scoring index improved the rate in group A patients compare to group B. This confirm results by other authors that increase the healing process of tendons following local administration of growth factors which were encourage by PRP injections [11, 16]. An injection of autologous blood for managing chronic plantar fasciitis has been reported, a prospective randomized study by Lee et al. compared autologous blood injection with corticosteroid injection. However, the intralesional autologous blood significantly decreased pain levels and increased tenderness thresholds over the six-month follow-up period, this outcome supported the results in our study of long term improvement post PRP therapy ${ }^{[10]}$. Barrett et al. applied a single injection of PRP in a pilot study of nine patients and reported $78 \%$ symptom resolution at short-term follow-up of two months ${ }^{[15]}$, this result confirms by our results outcome study in both scoring system, VAS and Roles-Maudsley score. Several systems are commercially available that allow efficient preparation for outpatient use of the PRP, when selecting a preparation system, as volume and amount of autologous blood drawn, centrifuge rate/time, leukocyte concentration must be zero, Red blood cell must be zero. Delivery method, activating agent, final PRP volume and final platelet and growth-factor concentration. Controversies regarding the optimal quantity of platelets and growth factors required for muscle and tendon healing still persist ${ }^{[24]}$, these confirm in our study of the amount and the times of therapy. Although in these studies clinically effectiveness of PRP is defined as more than at three to fourth times from the normal platelet concentration in one tube PRP concentrated preparations, with three to fourth time intralesional PRP $[15,17$, ${ }^{20]}$.

Di Giovanni et al. reported a significant decrease in pain at two years patients treated with these tendonitis, plus stretching protocol, with improvement in the functional outcome reach to $92 \%$, this is supported by our study with results of $94 \%$ after 24 months of follow up of these patients treated with Achilles Tendonitis and Intractable plantar fasciitis were treated by PRP therapy, plus stretching exercise [6].

\section{Conclusions}

We concluded that intralesional injection of PRP results is safe, plus significant reduction of inflammatory process, overcome improvement of pain, with high rate of functional outcome in compare to steroid intralesional injection for treatment of inflammatory soft tissue tendonitis, Achilles Tendonitis and intractable Plantar Fasciitis with a clinical follow up study for 2 Years.

\section{References}

1. Davis PF, Severud E, Baxter DE. Painful heel syndrome: results of nonoperative treatment. Foot Ankle Int. 1994; 15:531-535.

doi: 10.1177/107110079401501002. [PubMed] [Cross Ref]

2. Martin RL, Irrgang JJ, Conti SF. Outcome study of subjects with insertional plantar fasciitis. Foot Ankle Int. 1998; 19:803-811.

doi: $\quad 10.1177 / 107110079801901203$. [PubMed][Cross Ref]

3. Filardo G, Kon E, Della Villa S, Vincentelli F, Fornasari PM, Marcacci M. Use of platelet-rich plasma for the treatment of refractory jumper's knee. Int Orthop. 2010; 34:909-915. doi: 10.1007/s00264-009-0845-7.

4. Crawford F, Thomson C. Interventions for treating plantar heel pain. Cochrane Database Syst Rev, 2003. 3 CD000416 [PubMed]

5. Healey K, Chen K. Plantar fasciitis: current diagnostic modalities and treatments. Clin Podiatr Med Surg. 2010; 27:369-380. 10.1016/j.cpm.2010.03.002. [PubMed] [Cross Ref]

6. DiGiovanni BF, Nawoczenski DA, Lintal ME. Plantar Fascia-Specific Stretching Exercise Improves Outcomes 
in Patients with Chronic Plantar Fasciitis. A prospective clinical trial with two-year follow-up. J Bone Joint Surg. 2006; 88A:1775-1881. doi: 10.2106/JBJS.E.01281. [PubMed] [Cross Ref]

7. Ogden JA, Alvarez RG, Marlow M. Shockwave therapy for chronic proximal plantar fasciitis: a metaanalysis. Foot Ankle Int. 2002; 23:301-308. [PubMed]

8. Cyriax JH, Cyriax PJ. Illustrated manual of orthopaedic medicine. London: Butterworth, 1983.

9. Gosens T, Den Oudsten BL, Fievez E, van't Spijker P, Fievez A. Pain and activity levels before and after platelet-rich plasma injection treatment of patellar tendinopathy: A prospective cohort study and the influence of previous treatments. Int Orthop. 2012; 36:1941-1946. doi: 10.1007/s00264-012-1540-7.

10. Lee TG, Ahmad TS. Intralesional autologous blood injection compared to corticosteroid injection for treatment of chronic plantar fasciitis. A prospective, randomized, controlled trial. Foot Ankle Int. 2007; 28:984-990. doi: 10.3113/FAI.2007.0984. [PubMed] [Cross Ref]

11. Andia I, Sanchez M, Maffulli N. Tendon healing and platelet-rich plasma therapies. Expert Opin Biol Ther. 2010; 10:1415-1426.

doi: 10.1517/14712598.2010.514603. [PubMed][Cross Ref]

12. de Vos RJ, Weir A, van Schie HT. Platelet-rich plasma injection for chronic Achilles tendinopathy: a randomized controlled trial. JAMA. 2010; 303:144-149.

doi: 10.1001/jama.2009.1986. [PubMed] [Cross Ref]

13. Hall MP, Band PA, Meislin RJ. Platelet-rich plasma: current concepts and application in sports medicine. J Am Acad Orthop Surg. 2009; 17:602-608. [PubMed]

14. Malay DS, Pressman MM, Assili A. Extracorporeal shockwave therapy versus placebo for the treatment of chronic proximal plantar fasciitis: results of a randomized, placebo-controlled, double-blinded, multicenter intervention trial. J Foot Ankle Surg. 2006; 45:196-210. doi: 10.1053/j.jfas.2006.04.007. ]

15. Barrett S, Erredge S. Growth factors for chronic plantar fasciitis. Podiatr Today. 2004; 17:37.

16. Bosch G, van Schie HT, de Groot MW. Effects of platelet-rich plasma on the quality of repair of mechanically induced core lesions in equine superficial digital flexor tendons: a placebo-controlled experimental study. J Orthop Res. 2010; 28:211-217. [PubMed]

17. Eppley BL, Woodell JE, Higgins J. Platelet quantification and growth factor analysis from platelet-rich plasma: Implications for wound healing. Plast Reconstr Surg. 2004; 114:1502-1508. [PubMed]

18. Foster TE, Puskas BL, Mandelbaum BR. Platelet-rich plasma: from basic science to clinical applications. Am J Sports Med. 2009; 37:2259-2272. doi: 10.1177/0363546509349921. [PubMed] [Cross Ref]

19. Mishra A, Pavelko T. Treatment of chronic elbow tendinosis with buffered platelet-rich plasma. Am J Sports Med. 2006; 34:1774-1778.

doi: 10.1177/0363546506288850. [PubMed][Cross Ref]

20. Marx RE. Platelet-rich plasma: evidence to support its use. J Oral Maxillofac Surg. 2004; 62:489-496. doi: 10.1016/j.joms.2003.12.003. [PubMed] [Cross Ref]

21. Eppley BL, Woodell JE, Higgins J. Platelet quantification and growth factor analysis from platelet-rich plasma: Implications for wound healing. Plast Reconstr Surg. 2004; 114:1502-1508. [PubMed]
22. Gerritsen ME, Tomlinson JE, Zlot C. Using gene expression profiling to identify the molecular basis of the synergistic actions of hepatocyte growth factor and vascular endothelial growth factor in human endothelial cells. Br JPharmacol. 2003; 140(4):595-610. doi: 0.1038/sj.bjp.0705494.

23. Sánchez M, Anitua E, Azofra J, Andía I, Padilla S, Mujika I. Comparison of surgically repaired Achilles tendon tears using platelet-rich fibrin matrices. Am J Sports Med. 2007; 35:245-251. doi: 10.1177/0363546506294078. [PubMed] [Cross Ref] 